DOI https://doi.org/10.17308/vsu.proc.law.2021.3/3551

\title{
СТРУКТУРА МЕХАНИЗМА АДМИНИСТРАТИВНО-ПРАВОВОГО РЕГУЛИРОВАНИЯ
}

\author{
С. М. Рукавишников \\ Саратовская государственная юридическая академия \\ Поступила в редакцию 1 июля 2021 г.
}

\begin{abstract}
Аннотация: статья посвящена совершенствованию подходов к структурно-системной организаиии механизма адлинистративно-правового регулирования на основе общетеоретических представлений о механизле правового регулирования с учетол специфики предлета адлинистративного права. Актуальность статьи определяется задачами совершенствования содержания основных категорий адлинистративного права, поскольку выработка их совреленного понилания илеет большое значение, показывая гибкость общетеоретической терминологии, возложность ее дополнения, видоизменения и приспособления к сложившился в отрасли адлинистративного права и практике приленения его норм реалиял. Выявлены основные подходы к определению механизла правового регулирования в общетеоретическом и административно-правовол аспектах. Автор акиентирует внилание на таких особенностях адлинистративно-правового регулирования, как наличие практически организующего потенииала и возможность обеспечения всестороннего воздействия на социальные связи публичноуправленческого содержания. Авторол обоснована иелесообразность учета специфбки предмета адлинистративно-правового регулирования для определения элелентов структуры его механизма, что делает возложныли выделение, полимо общепризнанных элелентов, адлинистративно-правовых средств организующего воздействия на общественнье отношения и мер административно-правового убеждения, стилулирования и принуждения. Ключевые слова: государственное управление, структура механизла, адлинистративно-правовое регулирование, органы исполнительной власти, структурно-систелная организаиия.
\end{abstract}

Abstract: the article is devoted to improving approaches to the structural and systemic organization of the mechanism of administrative and legal regulation on the basis of general theoretical ideas about the mechanism of legal regulation, taking into account the specifics of the subject of administrative law. The relevance of the article is determined by the tasks of improving the content of the main categories of administrative law, since the development of their modern understanding is of great importance, showing the flexibility of general theoretical terminology, the possibility of its addition, modification and adaptation to the realities prevailing in the field of administrative law and the practice of applying its norms. The main approaches to determining the mechanism of legal regulation in general theoretical and administrative-legal aspects are identified. The author focuses on such features of administrative and legal regulation as the presence of practical organizing potential and the possibility of ensuring a comprehensive impact on social relations of public and managerial content. The author substantiates the expediency of taking into account the specifics of the subject of administrative and legal regulation to determine the elements of the

(C) Рукавишников С. М., 2021 
structure of its mechanism, which makes it possible to allocate, in addition to the generally recognized elements, administrative and legal means of organizing influence on public relations and measures of administrative and legal persuasion, stimulation and coercion.

Key words: state administration, mechanism structure, administrative and legal regulation, executive authorities, structural and system organization.

В юридической литературе вопросы структурно-системной организации механизма административно-правового регулирования не являются в достаточной степени исследованными для того, чтобы можно было сформировать корректное и полное понимание указанного механизма. Этому имеются объективные причины. Поскольку административное право как отрасль российского права имеет чрезвычайно широкий предмет, многочисленные исследования ученых-административистов направлены на оценку и определение перспектив развития отдельных его институтов, что имеет большую значимость, поскольку подобные исследования позволяют выработать рекомендации по улучшению правового регулирования и практической организации функционирования многочисленных отраслей и сфер государственного управления. На такие общие всеобъемлющие понятия, как предмет и механизм административно-правового регулирования, административно-правовые режимы, обращается меньшее внимание.

При этом исследователи, рассматривая частные вопросы административно-правового регулирования тех или иных социальных связей, в случае необходимости нередко ссылаются на соответствующие общетеоретические понятия и категории. Однако выработка их отраслевого понимания является не менее важной, поскольку показывает гибкость соответствующей терминологии, возможность ее дополнения, видоизменения и приспособления к сложившимся в отрасли административного права и практике применения его норм реалиям. Это может способствовать и обратному эффректу, когда сложившееся в науке административного права понимание данного термина может послужить предпосылкой коррекции взглядов ученых - теоретиков права. Указанные обстоятельства актуализируют постановку вопроса о структуре механизма административно-правового регулирования.

В философском понимании структуры (от лат. structure - порядок, расположение, строение) ее сущность определяется совокупностью устойчивых связей того или иного объекта, способствующих сохранению его основных свойств, несмотря на внутренние и внешние изменения. При этом структура является основной характеристикой системы, ее инвариантным аспектом ${ }^{1}$, поскольку остается неизменной в случае перехода к новым условиям и осуществления преобразований. В ином значении структура понимается как строение объекта, взаимосвязь и взаиморасположение его составных частей ${ }^{2}$.

${ }^{1}$ См.: Новая фрилософрская энциклопедия : в 4 т. М., 2010. Т. 3. С. 647.

${ }^{2}$ См.: Большой толковый словарь русского языка / под ред. С. А. Кузнецова. СПб., 2000. С. 1282. 
Если исходить из разных трактовок понятия структуры, то ключевым для правильного его восприятия является выделение составных частей, которые образуют не простую совокупность элементов, а комплекс взаимосвязанных составляющих, не изменяющих своих качеств под воздействием всевозможных изменений. Необходимо также проводить корреляцию структуры с парной для нее категорией - системой, определяющей состояние объекта, при котором совокупность элементов, находящихся в отношениях и связях друг с другом, образует некое единство, целостность ${ }^{3}$.

При рассмотрении механизма административно-правового регулирования необходим системный подход, направленный на то, чтобы показать его целостность как объекта исследования, обеспечивающие его конструкции, раскрыть разнообразие связей его элементов и объединить их в целостную теоретическую картину. В данном случае механизм административно-правового регулирования, представляя собой исследуемый объект, характеризуется наличием структурных элементов, находящихся друг с другом в состоянии системной взаимосвязи и взаимообусловленности.

Поскольку механизм административно-правового регулирования является одним из отраслевых механизмов, следует обратить внимание на общетеоретическое понимание механизма правового регулирования. Данное понятие, сформировавшееся как одна из ключевых категорий современной теории права, было обстоятельно исследовано С. С. Алексеевым, определившим его понятие, структуру и, по сути, современное понимание. Им была выявлена взаимосвязь между процессом правового регулирования и его механизмом. Если обозначенный процесс имеет три стадии (регламентация требующих юридического опосредствования социальных связей; действие норм права, в ходе которого возникают и изменяются правоотношения; реализация субъективных прав и юридических обязанностей, выраженная в поведении субъектов права, чем достигается цель правового регулирования), то им должны соответствовать три основных элемента механизма правового регулирования (нормы права; правоотношения; акты реализации субъективных прав и юридических обязанностей) ${ }^{4}$.

Названные элементы, характеризуясь свойством обязательности их наличия в механизме правового регулирования, дополняются и иными (фракультативными) элементами, являющимися результатом властного волеизъявления актами государственных органов, направленными на принудительное исполнение субъектом его обязанностей; обеспечивающими казуальную регламентацию социальных связей индивидуальными актами; нормативными правовыми актами; правовой культурой; правосознанием. Последние два элемента, по мнению С. С. Алексеева, имеют общезначимый характер, оказывая влияние на иные структурные элементы ${ }^{5}$.

${ }^{3}$ См.: Новая фрилософрская энциклопедия. Т. 3. С. 552.

${ }^{4}$ См.: Алексеев C. C. Механизм правового регулирования в социалистическом государстве. М., 1966. С. 34.

${ }^{5}$ См.: Там же. С. 35-38. 
Впоследствии понятие механизма правового регулирования получило широкое распространение, но при сходном подходе к определению его понятия определенным образом разнятся мнения относительно его системно-структурной организации. В частности, А. В. Малько указывает на такие элементы данного механизма, как правовая норма; юридический фракт (фактический состав), в первую очередь, организационно-исполнительный правоприменительный акт; правоотношение; акты реализации прав и обязанностей; охранительный правоприменительный акт, рассматриваемый в качестве факультативного элемента. Помимо этого, своего рода дополнительными элементами могут быть режим законности, правосознание, акты официального толкования норм права и пр. ${ }^{6}$

В научных источниках по теории права имеются и иные мнения по поводу структурирования элементов механизма правового регулирования. В частности, М. Ю. Спирин дополняет данный механизм универсальными принципами правового регулирования и внешними формами права ${ }^{7}$. Однако в целом можно выделить те элементы, наличие которых в данном механизме носит бесспорный характер и отмечается всеми исследователями - нормы права, правоотношения и акты реализации прав и обязанностей. Несмотря на наличие множества точек зрения, нельзя однозначно говорить о некорректности каких-либо из них, поскольку юридические средства, образующие содержание механизма правового регулирования, многообразны, а расстановка приоритетов в выделении тех из них, которые составляют указанный механизм, зависит от аргументации исследователя. К тому же с философской точки зрения в зависимости от условий поставленной перед исследователем задачи и сообразно предварительным данным эмпирического знания один и тот же объект может быть представлен в виде различных систем ${ }^{8}$, что относимо и к механизму правового регулирования.

В то же время следует указать на то, что любая система, складывающаяся в социуме, должна характеризоваться определенной последовательностью расположения частей, выделением первичного элемента, без которого невозможно проявление иных элементов и, собственно, формирование системы. Представляется уместным в данном случае исходить из учения С. С. Алексеева о стадийности процесса правового регулирования и соответствующего его стадиям наборе последовательно реализуемым элементам исследуемого механизма. В этом смысле его первичной частью должна быть норма права, образующая первооснову, которая опосредует возникающие на ее основе социальные связи. Последние, соответственно, являются вторым элементом, а в рамках этих отношений происходит реализация субъективных прав и юридических обязанностей

${ }^{6}$ См.: Матузов Н. И., Малько А. В. Теория государства и права : учебник. М., 2004. C. 472-473.

${ }^{7}$ См.: Спирин М. Ю. Механизм правового регулирования : место источников и истоков права в его структуре // Правовое государство : теория и практика. 2020. № 1 (59). С. 42.

${ }^{8}$ См.: Философрская энциклопедия : в 5 т. М., 1970. Т. 5. С. 140. 
их участников, что оформляется соответствующими актами и составляет последующий элемент механизма правового регулирования.

Перечисление названных элементов в ином порядке хотя и заслуживает внимания, но не является бесспорным. Подобные суждения встречаются в литературе по административному праву. Ставя на первое место принципы административного права, Н. В. Макарейко в качестве элементов структуры административно-правового регулирования называет нормы административного права; акты официального толкования этих норм; правоприменительные акты; административные правоотношения ${ }^{9}$. Аналогичные суждения ранее были высказаны А. П. Кореневым, объединившим, однако, в один целостный элемент структуры исследуемого механизма административно-правовые нормы и принципы административного права, находящие отражение в законодательстве, нормативных правовых актах Президента РФ и иных актах подзаконного регулирования социальных связей ${ }^{10}$. Подобная точка зрения, безусловно, имеет право на существование. Вместе с тем принципы административного права являются довольно пространной категорией. Для целей регламентации конкретных социальных связей в публично-управленческой сфрере используются принципы правового регулирования, которые так или иначе воплощены в нормах административного права, будучи обозначенными в законе именно в виде «принципов», либо вытекают из текста нормативного акта, выражая его глубинный смысл и социальное предназначение. Поэтому выделение в структуре механизма административно-правового регулирования данных принципов при наличии в нем норм административного права видится излишним.

Представляет также интерес рассмотрение механизма административно-правового регулирования как сложного явления, включающего комплекс органической и функциональной составных частей. Первая характеризует сущность данного механизма, сочетая в себе те его компоненты, без которых он не может считаться состоявшимся. Вторая определяет степень влияния вспомогательных элементов на рассматриваемый механизм, обеспечивая его эффективность и результативность. Функциональная часть способна оказывать качественное воздействие на механизм административно-правового регулирования, модифицируя его, что повышает его надежность. Так, более высокий уровень правосознания обеспечивает более действенную его реализацию. Однако отсутствие фрункциональной части не препятствует претворению в действительность механизма административно-правового регулирования ${ }^{11}$.

${ }^{9}$ См.: Макарейко Н. В. Административное право : учеб. пособие для вузов. 11-е изд., перераб. и доп. М., 2021. С. 31.

${ }^{10}$ См.: Коренев А. П. Административное право России : учебник : в 3 ч. М., 1999. Ч. 1. С. 43.

${ }^{11}$ См.: Аgбанасьев $K$. K. Механизм административно-правового регулирования : философско-правовые аспекты // Проблемы права : теория и практика. 2019. № 45. C. 108 . 
Высказанные в научной литературе суждения по поводу структурной организации механизма административно-правового регулирования вносят большой вклад в развитие науки административного права. В то же время целесообразно высказать и иные соображения по данному вопросу. Структура механизма административно-правового регулирования должна определяться спецификой последнего, которая выражается в следующем:

1) административное право обладает мощным организующим потенциалом, поскольку регулирует организационные общественные отношения, складывающиеся во всех областях, отраслях и сdрерах государственного управления. Данная отрасль права обеспечивает функционирование публичного (прежде всего, государственного) управления, связанного с деятельностью органов исполнительной власти, в которой воплощена практически организующая сила государства ${ }^{12}$. Этот фактор целесообразно учитывать при выявлении элементов структуры механизма административно-правового регулирования, основное содержание которых составляют административно-правовые средства воздействия на социальные связи публично-управленческого типа. С этой точки зрения в структуре рассматриваемого механизма в качестве отдельного элемента можно выделить административно-правовые средства организующего воздействия на общественные отношения, например административно-правовые средства организации получения высшего образования и подготовки научно-педагогических кадров или административно-правовые средства организации здравоохранения и обеспечения медицинского обслуживания населения и др.;

2) административно-правовое регулирование обеспечивает всестороннее воздействие на социальные связи публично-управленческого формата. Это воздействие может выражаться в убеждении, стимулировании и принуждении. В связи с этим в дополнение к теоретико-правовой конструкции, выработанной С. С. Алексеевым, который выделил в структуре механизма правового регулирования акты государственных органов, направленные на властно-принудительное исполнение субъектом его обязанностей, следует учитывать меры административно-правового поощрения и стимулирования, применяемые во многих отраслях и сферах государственного управления, в том числе в отраслях образования и науки ${ }^{13}$, в экономической области ${ }^{14}$ и др.

${ }^{12}$ См.: Конин Н. М. Административное право России : учебник. 2-е изд., перераб. и доп. М., 2010. С. 15.

${ }^{13}$ См., например: Белоусов С. А., Кротов К. С. Ученое звание как составляющая профессионального статуса научно-педагогических работников в России и зарубежных странах // Правовая политика и правовая жизнь. 2020. № 2. С. 8899 ; Соколов А. Ю., Лакаев О. А. Возможные направления совершенствования института ученых званий в России // Вестник Саратовской гос. юрид. академии. 2020. № 5 (136). С. 129-138.

${ }^{14}$ См., например: Лакаев О. А. Особенности деятельности субъектов государственного управления по организации и обеспечению административно-правового режима зон территориального развития // Административное право и процесс. 2020. № 3. C. 17-20. 
Таким образом, учитывая общетеоретические представления о структуре механизма правового регулирования и специфику предмета административно-правового регулирования, можно выделить такие элементы структуры его механизма, как: 1) административно-правовые нормы; 2) административные правоотношения; 3) акты административного правоприменения; 4) административно-правовые средства организующего воздействия на общественные отношения; 5) меры административно-правового убеждения, стимулирования и принуждения. При этом данный механизм должен характеризоваться гибкостью, учитывающей специфику каждой отрасли и сферы государственного управления. Неизменный набор первых трех элементов применительно к каждой из указанных сорер и отраслей должен дополняться собственными средствами организующего воздействия, своим подбором мер административно-правового убеждения, стимулирования и принуждения.

\section{Библиографический список}

Алексеев C. С. Механизм правового регулирования в социалистическом государстве. М. : Юрид. литература, 1966. 187 с.

Аøбанасьев $K . K$. Механизм административно-правового регулирования : фрилософрско-правовые аспекты // Проблемы права : теория и практика. 2019. № 45. C. 103-114.

Белоусов С. А., Кротов К. С. Ученое звание как составляющая профрессионального статуса научно-педагогических работников в России и зарубежных странах // Правовая политика и правовая жизнь. 2020. № 2. С. 88-99.

Большой толковый словарь русского языка / под ред. С. А. Кузнецова. СПб. : Норинт, 2000. 1536 с.

Конин Н. М. Административное право России : учебник. 2-е изд., перераб. и доп. М. : Проспект, 2010. 448 с.

Коренев А. П. Административное право России : учебник : в 3 ч. М. : Щит-М, 1999. Ч 1.280 с.

Лакаев О. А. Особенности деятельности субъектов государственного управления по организации и обеспечению административно-правового режима зон территориального развития // Административное право и процесс. 2020. № 3. C. 17-20.

Макарейко Н. В. Административное право : учеб. пособие для вузов. 11-е изд., перераб. и доп. М. : Юрайт, 2021. 280 с.

Матузов Н. И., Малько А. В. Теория государства и права : учебник. М. : Юристъ, 2004. 512 с.

Новая фрилософрская энциклопедия : в 4 т. М. : Мысль, 2010. Т. 3. 692 с.

Соколов А. Ю., Лакаев О. А. Возможные направления совершенствования института ученых званий в России // Вестник Саратовской гос. юрид. акад. 2020. № 5 (136). С. 129-138.

Спирин М. Ю. Механизм правового регулирования : место источников и истоков права в его структуре // Правовое государство : теория и практика. 2020. № 1 (59). С. 37-45.

Философрская энциклопедия : в 5 т. М. : Советская энциклопедия, 1970. T. $5.740 \mathrm{c}$. 


\section{References}

Alekseev S. S. The mechanism of legal regulation in the socialist state. Moscow : Legal literature, 1966. $187 \mathrm{p}$.

Afanasyev K. K. The mechanism of administrative and legal regulation: philosophical and legal aspects // Problems of law: theory and practice. 2019. № 45. P. 103-114.

Belousov S. A., Krotov K. S. Academic title as a component of the professional status of scientific and pedagogical workers in Russia and foreign countries // Legal policy and legal life. 2020. № 2. P. 88-99.

Large explanatory dictionary of the Russian language / Edited by S. A. Kuznetsov. St. Petersburg : Norint, 2000. 1536 p.

Konin N. M. Administrative law of Russia: textbook. 2nd ed., reprint. and additional. M.: Prospect, 2010. 448 p.

Korenev A. P. Administrative law of Russia. Textbook. In 3 parts. Part I. M. : Shield-M, 1999. 280 p.

Lakaev $O$. A. Features of the activities of state administration entities on the organization and maintenance of the administrative and legal regime of territorial development zones // Administrative law and process. 2020. № 3. P. 17-20.

Makareiko N. V. Administrative law: a textbook for universities. 11th ed., reprint. M. : Yurayt, 2021. 280 p.

Matuzov N. I., Malko A. V. Theory of State and law: textbook. M. : Yurist, 2004. $512 \mathrm{p}$.

The New Philosophical Encyclopedia. In 4 vols. Vol. 3. M. : Mysl, 2010. 692 p.

Sokolov A. Yu., Lakaev O. A. Possible directions for improving the Institute of academic titles in Russia // Bulletin of the Saratov State Law Academy. 2020. № 5 (136). P. 129-138.

Spirin $M . Y u$. The mechanism of legal regulation: the place of sources and sources of law in its structure // The legal state: theory and practice. 2020. № 1 (59). P. 37-45.

Philosophical Encyclopedia. In 5 t. t. 5. M. : Soviet Encyclopedia, 1970. 740 p.

\section{Для иитирования:}

Рукавишников С. М. Структура механизма административно-правового регулирования // Вестник Воронежского государственного университета. Серия: Право. 2021. № 3 (46). C. 201-208. DOI: https://doi.org/10.17308/vsu.proc.law.2021.3/3551

\section{Recommended citation:}

Rukavishnikov S. M. Structure of the mechanism of administrative and legal regulation // Proceedings of Voronezh State University. Series: Law. 2021. № 3 (46). P. 201-208. DOI: https://doi.org/10.17308/vsu.proc.law.2021.3/3551

Саратовская государственная юридическая акаделия

Рукавишников С. М., кандидат юридических наук, докторант кафбедры административного и муниципального права

E-mail:Privet085@gmail.ru

\section{Saratov State Law Academy}

Rukavishnikov S. M., Candidate of Legal Sciences, Doctoral Student of the Administrative and Municipal Law Department E-mail:Privet085@gmail.ru 